\title{
Ferreira, M. P. (2016). Musical Exchanges, 1100-1650: Iberian Connections. Kassel: Reichenberger, 392 pp. ISBN: 978-3-944244-57-0
}

Aunque esta reseña llegue con cierto retraso con relación a la fecha de su publicación, merece la pena presentar los contenidos de este libro colectivo en un momento en el que las dificultades para trabajar sobre el patrimonio musical se han incrementado notablemente. Cualquier seguidor de The Avengers podrían calificar como "lapso" lo sucedido en este último año 2020, en el cual hemos visto cómo se ha detenido buena parte de la actividad investigadora que se desarrolla en archivos, dadas las difíciles condiciones de consulta propiciadas por la pandemia. Esto, sin duda, ha permitido una lectura más detenida y sosegada de lo mucho y bueno que en los tiempos recientes se ha publicado, aunque llegue a nuestras manos algo envejecido como sucede con los vinos nobles.

La música en la Península Ibérica ha sido estudiada dentro de una burbuja territorial condicionada por sus marcas geográficas, poco permeables a una perspectiva interregional. Sin embargo este trabajo colectivo desbroza los caminos de intercambio, influencia y circulación de los materiales e influencias musicales entre los años 1100 y 1650 con el acierto que veníamos presintiendo muchos como necesario, habida cuenta de las concomitancias y conjunciones que estos estudios traen a la luz. La responsabilidad de esta empresa es de Manuel Pedro Ferreira, profesor en la Universidade Nova de Lisboa y cátedra CESEM (Centre for Research on Sociology and Aesthetics of Music). Miembro del comité académico de la International Musicological Society, ha sido reconocido tanto por su actividad como músico práctico, director del conjunto Vozes Alfonsinas, como por su excelencia musicológica -editor del Cancioneiro Elvas (Lisboa, 1989), O Som de Martín Codax (Lisboa, 1986, Premio del Conselho Português da Música), Antologia de Música em Portugal na Idade Média e no Renascimento (Lisboa, 2008, 2 vols), Medieval Sacred Chant: from Japan to Portugal (Lisboa, 2008), A Sé de Braga. Arte, Liturgia e Música, do final do século XI à época tridentina (Lisboa, 2009), Aspectos da Música Medieval no Ocidente Peninsular (Lisboa, 2009-2010, 2 vols.), Revisiting the Music of Medieval France: from Gallican chant to Dufay (Farnham-Burlington, 2012), Harmonias do Céu e da Terra: A música nos manuscritos de Guimarães (séculos XIIXVII) (Lisboa-Guimarães, 2012). Un vistazo, pues, a sus publicaciones precedentes nos permite contextualizar de donde nace este profundo interés por diseñar los canales comunicantes que transfieren de Europa a la península y viceversa aspectos que atañen al estilo, fijación, función y escritura de los repertorios. De hecho, el volumen se nutre de un encuentro previo que alimentó la discusión, celebrado en junio de 2012 en el título Musical Exchanges, 1100-1600: The Circulation of Early Music in Europe and Overseas in Iberian and IberianRelated Sources. 
En su clarividente introducción -"Emmulation and Hybridation in Iberia: A Medieval Background” (pp. 3-17)-, Manuel Pedro Ferreira subraya las últimas investigaciones sobre el canto mozárabe, la iberia islámica, la intervención instrumental en los tipos rajal y muwashshah, los desarrollos litúrgicos, las canciones trovadorescas, aquellas otras populares y devocionales, y la temprana polifonía, apuntando a los últimos estudios que asentarán las bases de los trabajos que se suceden a continuación. La primera sección dedicada a una reflexión sobre la monodia se inicia con el trabajo de Arturo Tello RuizPérez, quien en su "Center and Periphery Again: Could Spain be Considered an Independent Tradition of Liturgical Song?” (pp. 21-29) plantea, a través de varios ejemplos sobre la homogeneidad de nuestra tradición, sus dudas sobre el centro y la periferia de Cluny y el espacio que ocupa la tradición catalana. Kathleen E. Nelson, en su "The Notated Exultet in Braga's Missal de Mateus: Known Tradition or New Composition?”, examina las características de este fragmento para el cual halla paralelos interesantes en fuentes francesas -Limoges- y españolas -Toledo y Sevilla-. Diogo Alte da Viega en "Twelfth and Thirteenth Century Breviary Fragments in Moissac and the Rite of Braga: Some Preliminary Insights" (pp. 49-58), sigue la trayectoria de Gerald de Moissac, quien antes de llegar a Braga como obispo había sido bibliotecario y maestro de ceremonias en el monasterio cluniacense de Moissac había estado el priorato de La Daurade en Tolouse y figurado como director de coro en la catedral de Toledo. Su examen le permite mantener la hipótesis de que los himnarios estudiados de Moissac, Braga y Huesca pudieron tener una fuente común. Kate Helsen utiliza en su artículo "The European Affiliations of Ms. Port BPM 1151" (pp. 59-68) el moderno concepto poético de Pessoa "heterónimo" para examinar la fuente del manuscrito a la luz de sus tres posibles orígenes radicados en el Monasterio de Santa Cruz (Coimbra), Braga y Santiago de Compostela, como posibles legitimadores de su posible "biografía" documental. Cierra esta sección Raúl Araújo, quien estudiará en su "Trouvère Elements in the Cantigas de Santa María" (pp. 69-86) las concordancias del corpus alfonsino con otros diez códices de la lírica trovera -Bern, Burgerbilbliothek, MS 231; y en la Bibliothèque Nationale de France los códices f. fr. 756; f. fr. 844-847; f. fr. 1591; f. fr. 12615; f. fr. 24406; y n.a. fr. 1050- con el fin de delimitar las posibilidades de contrafacta, influencia o afinidad estilística, o bien caracterizar un mero compartimiento melódico coincidente.

La segunda parte de este libro -y más extensa- se dedica íntegramente a la polifonía y a los posibles intercambios musicales entre sus actantes. Inicia esta sección el trabajo de Bernardette Nelson "Urrede's Legacy and Hymns for Corpus Christi in Portuguese Sources: Aspectos fo Musical Transmission and Influence” (pp. 89-116), quien examina la presencia del Pange lingua de Urrede en ciertas fuentes contenidas en Coimbra a pesar de la inexistencia - por el momento- de copias de principios del XVI de la obra del autor flamenco. Juan Ruiz Jiménez estudiará en su "Himnario de la catedral de Sevilla versus Intonarium Toletanum (Alcalá de Henares, 1515)" (pp. 117-1164) las concordancias y particularidades textuales, así como la asignación litúrgica y naturaleza musical, del primero -escrito en notación no mensural, con veintidós melodías diferenciadas- con respecto del segundo. Las tablas que incorpora sugerirán notables puntos de contacto entre himnarios lusitanos, toledanos e hispalenses que proporcionan nuevas perspectivas para comprender la circulación del repertorio himnódico, monódico y polifónico entre las coronas de Castilla 
y Portugal. En "Some Identifying Features of Late-Fifteenth- and Early-Sixteenth- Century Portuguese Polyphony” (pp. 165-190), João Pedro d'Alvarenga encontrará en Vasco Pires maestro de capilla hasta su indeterminada muerte (probablemente anterior a 1547) en la Catedral de Coimbra, donde ya fue cantor desde 1581- influencias de Urrede y elementos estilísticos de Juan del Encina, Pedro Escobar y de Juan de Anchieta, probablemente en un proceso escritural que trataba de emular las características distintivas del estilo imitado al tiempo que existía una cierta preocupación por amplificarlos.

Owen Rees examinará en su "The Coimbra Manuscripts and the 'Spanish Court Repertory': The Motet Peccavi Domine" (pp. 191-208) la colección de manuscritos conservados en la Biblioteca Geral da Universidade de Coimbra procedentes del monasterio agustino de Santa Cruz, entre los que se encuentra la obra de Pedro Sousa, al servicio en la corte de los Reyes Católicos -después retornado a Portugal para ser luego maestro de capilla en Valencia y regresar finalmente a la corte de Évora. Él y Pedro de Escobar se identifican como posibles responsables de la transmisión de la polifonía española al país vecino. Estudia así los MM12 y MM 32 como testimonios del repertorio sacro español y, dentro de esta última fuente, focaliza su estudio en el motete Peccavi domine, sin atribución de autoría, comparado con otras facturas de Francisco de Peñalosa, apoyado sobre los estudios de Tess Knighton. Es precisamente esta autora la responsable del estudio que le sucede -“Gonçalo de Baena's Arte para tanger (Lisboa, 1540): Local and International Repertoires" (pp. 209-239)-, en el que identifica y define los compositores representados en esta fuente -desde Agricola, Brumel, Obrecht, Urrede, Anchieta, Badajoz, Escobar, Josquin, hasta Basurto o Morales, quienes abarcan un siglo de música- para analizar después con detalle las acomodaciones que realiza de las catorce obras que incorpora de Josquin. Emilio Ros-Fábregas en su "Franco-Flemish Polyphony versus Palestrina in Spanish Choirbooks with Renaissance Repertory and the Case of Barcelona, Biblioteca de Castaluya, M.682: Towards a Revised Census-Catalogue" (pp. 240-264) nos ofrecerá un complejo acervo de cuatrocientos tres libros de coro procedentes del siglo XV al XVIII contenidos en las bibliotecas y archivos por él examinados, en los que puede constatarse un enorme contraste entre el repertorio no ibérico copiado en el siglo XVI -la mayor parte corresponde a obra franco-flamenca- y la música copiada entre los siglos XVII y XVIII, orientada esencialmente hacia Palestrina. Contextualizará el valor de las recopilaciones de los cancioneros de la Colombina, Palacio y Segovia y analizará, entre otros factores, el papel de la inmigración francesa en Cataluña. Ya en el ámbito de la música en América, Omar Morales Abril, en su "Presencia de música y músicos portugueses en el virreinato de la Nueva España y la provincia de Guatemala, siglos XVI-XVII” (pp. 265-293) analizará los procesos migratorios de portugueses al nuevo mundo y concretará con acertado detalle ciertos aspectos de la biografía de Gaspar Fernández que conciernen a su nombramiento como maestro de capilla en la Catedral de Guatemala, así como a su dudosa condición simultánea de organista y maestro de capilla. El hecho más relevante es su minucioso estudio sobre la identidad del músico, al demostrar que Gaspar Fernández no pudo ser el cantor de la catedral de Évora allí presente hasta al menos 1599 y, al mismo tiempo, el compositor de la música del Códice de Oaxaca, activo desde 1596. Propone así la novedosa hipótesis, apoyada sobre fuentes documentales, de una identidad criolla o castiza nacida en la demarcación del obispado o en la misma provincia de Guatemala, significando así el alto 
grado de apropiación regional que se alcanzó del lenguaje musical europeo. El capítulo concluye con un interesante inventario que recoge las músicas de los compositores portugueses entre los siglos XVI y XVIII.

La tercera sección del libro lleva por título Other Sources, Other Connections y viene a clausurar esta visión "suprarregional" del patrimonio histórico, con tres estudios en cierto modo tangenciales - cuando no sin relación alguna- a la península ibérica: "Collatum miseris: A Little-Known English Liturgical Office for St. James. Politics and Plainchant in the Time of Henry II", de David Hiley (pp. 301-312); el artículo de Thomas Forrest Kelly "Bevenventan Sources in Iberia" (pp. 313-329), que identifica las fuentes del canto beneventano en un utilísimo apéndice final que recoge los códices contenidos en archivos y bibliotecas de Coimbra, Oporto, Barcelona, El Escorial, la catedral de Girona, el Archivo Histórico Nacional, la Biblioteca Nacional, la Biblioteca Capitular de Toledo o el Monasterio de Montserrat; y el trabajo de Ana Gaunt, "The Arauca Polyphonic Codex" (pp. 330-342), quien no solo analiza el repertorio o la procedencia y ascendencia de los copistas -copiada hacia 1615 y vinculado a la tradición del Císter-, sino que se detiene en las anotaciones manuscritas por una o por varias manos diferenciadas y que competen a la ejecución instrumental en contextos litúrgicos o a las distintas formas de interpretación vocal.

El libro concluye así con una cuidadosa ordenación de las fuentes primarias citadas en todos los trabajos (pp. 343-360) y las fuentes secundarias consultadas (pp. 361-387), con un breve índice onomástico de lugares y compositores (pp. 388-389). Esta recopilación de estudios, en definitiva, pone en manos del lector un volumen excepcional que recoge nuevas vías, caminos y pautas en la investigación para avanzar y conocer con mayor profundidad y tino los intercambios dados no solo dentro de la península, sino en sus conexiones con el viejo y el nuevo mundo.

\section{Juan José Pastor Comín}

Universidad de Castilla-La Mancha

Centro de Investigación y Documentación Musical (CIDoM)-Unidad Asociada al CSIC

ORCID iD: https://orcid.org/0000-0001-8165-1232 